\title{
"LEGÍTIMA DEFESA DA HONRA E OUTRAS LOUCURAS": A RELAÇÃO MÍDIA E SOCIEDADE ATRAVÉS DO SERIADO MALU MULHER
}

\section{“LEGITIMATE DEFENSE OF HONOR AND OTHER MADNESS": THE MEDIA AND SOCIETY RELATIONSHIP THROUGH THE SERIES MALU MULHER}

\section{Clarissa de Souza Oliveira Godoy}

Resumo: Este artigo examina a relação entre os meios de comunicação de massa, especificamente a televisão brasileira, e o movimento feminista brasileiro no final dos anos setenta, período em que tais movimentos estavam consolidando suas pautas e demandas no Brasil. Será apresentado a representação do feminismo no seriado Malu Mulher, através da análise de um dos capítulos, buscando entender as possibilidades de contribuição para a divulgação do movimento feminista e qual corrente feminista se tornou protagonista do seriado. Tal análise se baseia na discussão de uma das principais pautas do movimento feminista dos anos 1980 que foi a violência doméstica.

Palavras-chave: Feminismo. Televisão. Sociedade. Violência Doméstica

Abstract: This article examines the relationship between the mass media, specifically Brazilian television, and the Brazilian feminist movement in the late 1970s, when such movements were consolidating their patterns and demands in Brazil. It will be presented the representation of feminism in the series Malu Mulher, through the analysis of one of the chapters, seeking to understand the possibilities of contribution to the dissemination of the feminist movement and which current feminist became protagonist of the series. This analysis is based on the discussion of one of the main guidelines of the 1980s feminist movement that was domestic violence

Keywords: Feminism. Television, Society. Domestic Violence.

\footnotetext{
* Mestre em História pela Universidade Federal do Estado do Rio de Janeiro (PPGH/UNIRIO). Professora de História do Inest - Pré-vestibular comunitário. E-mail: clarissasgodoy@gmail.com.
} 


\section{INTRODUÇÃO}

A série Malu Mulher foi exibida pela Rede Globo, idealizada por Daniel Filho, escrita por Manoel Carlos, Lenita Plonczynski, Euclydes Marinho e outros. Foi dirigida por Denis Carvalho e Afonso Grisolli. No total, o seriado teve 76 capítulos que foram divididos em duas temporadas: a primeira em 1979 e a segunda em 1980. Cada capítulo tinha cerca de 45 minutos de duração e era exibido às quintas-feiras, no primeiro ano, e as segundas-feiras, no segundo, sempre no horário das $22 \mathrm{~h}$.

A trama girava em torno da vida da personagem Malu, protagonizada pela atriz Regina Duarte, uma mulher de classe média, paulistana, socióloga e disposta a ajudar quem the procurasse. Era também mãe de Elisa, interpretada por Narjara Turetta, insatisfeita com o seu casamento, e por isso pede a separação do então marido Pedro Henrique, interpretado por Denis Carvalho.

A abordagem pioneira do seriado ao tratar de temas que desafiavam o padrão "moral brasileiro" foi importante para a história da televisão brasileira, além de colaborar para uma nova forma de representar a mulher ao mostrar suas complexidades ao lidar com situações adversas. Nem sempre os temas abordados pelo seriado eram vividos por Malu, mas em sua maioria por personagens itinerantes, interpretados por atores e atrizes convidados, que cruzavam pelo seu dia-a-dia. Em muitos capítulos, a protagonista figurou como uma mediadora das situações difíceis que aconteciam ao seu redor. As decisões, muitas vezes complexas, eram tomadas de forma impulsiva no intuito de ajudar as mulheres que a cada episódio orbitavam ao seu redor. Este ponto poderá ser observado no capítulo selecionado para análise nesse artigo: "Em legítima defesa da honra e outras loucuras", que foi ao ar em 22 de Setembro de 1980.

As lutas referentes as pautas feministas podem ser percebidas ao longo do seriado, assim como os reflexos de uma sociedade vivida sob a ditadura civil militar. Não são poucos os episódios em que Malu comenta em tom irônico "Não vivemos em uma democracia? Não é isso que os jornais dizem? Então temos que cobrar" fazendo referência a ditadura civil militar que suprimia os direitos democráticos dos cidadãos, mas insistiam em divulgar e propagandear que o Brasil vivia um regime 
democrático de direito. A entonação proferida pela personagem referindo-se a falsa democracia que o país vivia reforça o tom crítico a ditadura

No contexto de luta pela democracia nacional Malu se aproxima do discurso das feministas da década de 1970 que aliam suas pautas primeiras em prol da igualdade entre homens e mulheres e ao combate o inimigo comum, no caso em questão a ditadura. Segundo essa teoria, somente com a democracia reestabelecida seria possível resolver as questões classistas de desigualdade. Por outro lado, muitos temas apresentados pelo seriado reivindicam questões específicas que viriam a ser consolidadas pelas feministas da década de 1980 como os direitos sobre o próprio corpo, liberdade sexual e direito ao aborto. É a partir destas pautas que se fará a análise do capítulo selecionado, investigando juntamente a posição política e feminista da personagem. Portanto para além do tom combativo em relação a situação política do Brasil naquele momento, o seriado explora assuntos fundamentais da agenda feminista da década de 1980.

O discurso de Malu era repleto de críticas sociais, em especial à ditadura civil militar. Sua posição não era assumida feminista, talvez para contrabalançar com a questão da censura e com o próprio feminismo que ela reivindicava. (ALMEIDA, 2012). O discurso generalizante como "não têm que ser questão de raça, nem feminista, mas de gente. Todos têm que ter direitos iguais" está presente ao longo do seriado, reafirmando um posicionando político que silencia certas identidades.

Sobretudo, a presença de um discurso do apaziguamento político, é marcante em Malu Mulher, dado pelo momento histórico que o Brasil vivia. Segundo o historiador Daniel Arão Reis (2014), nos anos finais da ditadura civil militar, a ala conservadora da classe média passa a almejar o fim da repressão política. Atentando para as mulheres desse grupo conservador brasileiro, Cordeiro (2016) aponta o surgimento de discursos pró democracia, fortalecendo, assim, parte da luta das feministas de esquerda e chegando ao "momento do consenso político." (REIS, 2014). Ou seja, não era mais interessante a manutenção da ditadura para a direita e já não era há décadas para a esquerda, portanto o posicionamento político do seriado, através das falas da personagem, também representa esse momento de coesão política entre as duas correntes. As falas generalizantes de Malu podem ser interpretadas como a mediação dessas mulheres de direita, que passam a se 
posicionar contra a tortura praticada ao longo da ditadura e apoiar o retorno a democracia.

Assim, Malu Mulher representa um feminismo liberal, que foi uma corrente do movimento mais popularizada, que norteou um padrão feminista no Brasil desde meados dos anos 1970 até se concretizar na década de 1980, e a serie colaborou para popularizar suas ideias e não outras formas de feminismos, como o radical ou o socialista. O lema "o pessoal é político" se consolida no Brasil apenas nos anos 1980 em especial pela mudança de pauta das próprias feministas e pela mudança política do país que inicia a abertura da ditadura civil militar. No final dos anos 70 , quando o Brasil já havia passado por uma certa prosperidade econômica, além do acesso aos ideais liberais por grande parte da sociedade, inclusive de grupos de mulheres e feministas, a corrente escolhida para prosperar os anseios do movimento serão os liberais.

Não seria inteligente da Rede Globo de Televisão exibir um programa de cunho feminista que não legitimasse a corrente do movimento que apoiava. Enquanto veículo de comunicação de massa a emissora colabora com a disseminação dos ideias feministas, mas antes ela determina que ideologia feminista irá propagandear. Assim, ela também elege que tipo de mulheres feministas quer para o Brasil, principalmente quando convocaram a atriz Regina Duarte para ser a protagonista. Era uma profissional respeitada pelo público da Rede Globo, famosa pelo título "queridinha do Brasil", por coincidência, em sua vida particular passava por um divórcio, tema do primeiro capítulo do seriado, legitimando assim os temas abordados pelo seriado, construindo um público para o seriado, já fiel aos trabalhos anteriores da atriz. (ALMEIDA, 2012). Por isso, as feministas interessantes para a mídia eram àquelas escolarizadas, bonitas, vaidosas, independentes financeiramente e em busca de sua liberdade sexual. Estas características básicas das liberais são o estereótipo que Malu representa e que, consequentemente, silencia outras correntes do movimento e outras possibilidades de ser feminista. Dificulta, portanto, que o público conheça as diferentes formas de feminismo para escolher aquele que mais the representa perante a sociedade.

A crítica que coloco é fundamental para posicionar politicamente este artigo diante da relação feminismo e mídia brasileira. Reconhecer as articulações pré- 
estabelecidas pelos veículos de comunicação de massa para divulgar seus interesses políticos é ainda um privilégio na sociedade brasileira atual. Portanto, desenvolver análises minuciosas sobre a produção midiática no Brasil deve ser de maior reivindicação do campo da história, para, assim, colaborar com outros campos do conhecimento que se debruçam há mais tempo sobre o problema, na tentativa de chamar atenção para a questão que permanece formando cidadãos não críticos ao sistema. É necessário desenvolver discussões sob uma perspectiva histórica, mostramos a formação do movimento feminista brasileiro, assim como sua consolidação enquanto movimento liberal e sua legitimação através de um veículo de comunicação de massa.

\section{MALU MULHER: VIOLÊNCIA DOMÉSTICA NO CENÁRIO BRASILEIRO DOS ANOS 80}

O episódio "Em legítima defensa da honra e outras loucuras", foi escrito por Armando Costa, dirigido por Denis Carvalho. Dividido em dois núcleos principais, cujo primeiro é centrado em Malu, que interage com Elisa, sua filha e uma moradora de seu prédio, e o segundo focando no casal de vizinhos Clarice e Duca, um casal de vizinhos interpretados por Marilia Pera e Gianfrancesco Guarniere.

A história começa com Malu e Elisa incomodadas com o barulho da briga vinda do apartamento ao lado. A relação que mãe e filha compartilham é de muita cumplicidade, construída especialmente pelo tipo de educação que Malu quis proporcionar a filha. Elisa é uma pré-adolescente com opiniões coerentes que são estimuladas cotidianamente pela mãe. A relação de troca entre as duas fortalecemnas enquanto mulheres, especialmente para a filha, que está em processo de amadurecimento.

Elisa se desespera e pede para a mãe ajudar a vizinha que estava apanhando do marido. Malu, tão indignada quanto a filha, pondera que é uma situação delicada, não podendo entrar na privacidade do casal, mesmo o caso sendo dramático. No instante seguinte, Clarice pede abrigo no apartamento da amiga. Alarmada e desorientada, ela não consegue se expressar com clareza, ora 
afirmando que o marido era um covarde, ora defendendo-o por ser um bom companheiro.

Clarice e Duca são casados há muitos anos e vizinhos de porta de Malu desde que Elisa era bebê. Ela é uma dona de casa, de mais ou menos 30 anos, que deseja maior independência, apesar de não ter renda própria. Ele aparenta ser um pouco mais velho que a esposa, trabalha fora de casa e assume o papel de provedor financeiro do lar. Clarice tem uma postura acuada e tímida, um tom de voz baixo e um discurso conciliador, dito com a cabeça meio para baixo. Suas roupas são simples, comuns as de uma dona de casa que vive para o marido, que não tem independência para comprar ou usar o tipo de roupa que quiser. Enquanto Duca é um homem grosseiro, que expressa sua opinião através da ironia, desdenhando do posicionamento de mulheres independentes, como é o caso de Malu. Seu tom de voz é áspero, usa roupas como camisa e calça social. A violência está presente no suor constante do personagem, no rubor do rosto quando é contrariado por Malu e pelo toque repressor no ombro da esposa quando estão na presença da vizinha.

Vale ressaltar que legítima defesa da honra e da dignidade era uma tese que consistia no fato de que a infidelidade de um dos cônjuges afrontava os direitos do outro e um insulto à sua honra e moral. Segundo o código penal brasileiro a ofensa à honra é capaz de desencadear uma série de efeitos emocionais sobre a pessoa do ofendido, precisamente no que diz respeito à honra conjugal. Numa leitura feminista, democrática, a tese da legítima defesa da honra é a construção do discurso que sobrepõe a honra do homem sobre o direito de viver garantido a mulher, portanto não deve ser considerada como justificativa para homicídio ou tentativa do mesmo.

O conflito emocional da vítima é notado pela incoerência de seu discurso e pela insegurança em falar sobre as agressões que sofre pelo marido. A personagem mal consegue verbalizar que é agredida cotidianamente, numa mistura de sentimentos que vai desde a vergonha ao medo. A tentativa de apaziguamento é interrompida por Duca, o agressor, ao convidar a mulher a retornar para a casa, garantindo para Malu que tudo não passava de um mal-entendido, que na realidade a esposa tentara trocar uma lâmpada e se machucou. Nesse momento o ângulo da câmera muda, com um close na mão do marido pressionando o ombro da esposa. Ele continua falando que tudo não passou de um acidente enquanto a câmera dá um 
segundo close em sua mão que permanece pressionando o ombro da mulher. Esse conjunto de closes representa a ameaça que Clarice sofre, principalmente naquele momento para confirmar sua versão dos fatos, ou seja, para manter a esposa coagida em frente da vizinha. Malu confronta Duca afirmando com ironia que Clarice estava constantemente machucada e que devia trocar menos as lâmpadas de casa.

A situação da violência doméstica é representada pelo seriado de maneira cirúrgica. É mostrado desde os primeiros argumentos incoerentes de quem é agredida e ainda está em estado de choque, passando pela orientação de outros personagens que divulgam os grupos de auxílio às mulheres vítimas de violência, ao ciclo de agressão que é retomado dentro do lar e terminando com uma situação drástica que aparentemente encerra o problema.

$\mathrm{Na}$ cena seguinte, Clarice adentra o apartamento de Malu em busca de refúgio por causa de uma nova agressão do marido. A sala está aparentemente escura, a câmera mostra em primeiro plano uma luminária acesa, que fica sobre a mesa de jantar, e é possível enxergar a personagem de Marília Pera em segundo plano, sob a penumbra da sala. Ela chora, se culpa por ter deixado a situação chegar a tal ponto e lamenta por não saber o que fazer, afinal de contas "eu sou só uma mulher" afirma a personagem, mostrando a fragilidade física diante da covardia do marido. O ângulo da câmera muda, mostrando agora Malu, iluminada sob a luz da luminária. Ela reafirma solidariedade à Clarice, oferece sua casa como morada, alerta sobre a necessidade de falar sobre o ocorrido e principalmente sobre denunciar para a polícia. A posição de Malu nesse momento é, para além da amizade, é de uma mulher ciente sobre a circunstância da violência doméstica. Tal ideia é reafirmada pelo jogo cênico escolhido para narrar a cena, ou seja, a oposição sombra e luz em que cada personagem é colocada. Representa assim, para o telespectador, que Clarice era uma mulher vítima de violência sem recursos psicológicos para sair de tal situação, enquanto Malu era a mulher esclarecida que a ajudaria resolver o problema.

O roteiro deste capítulo tem uma preocupação interessante em reproduzir os discursos do senso comum sobre a violência doméstica e ao mesmo tempo critica-lo de forma contundente. Ao conversar com o agressor, Malu tenta entender o que the motiva a agredir a esposa. Neste momento, os argumentos mais rasos e vazios são 
apresentados pelo marido, como o fato de a mulher querer ter um carro, usar batom vermelho ou sair para dançar só com amigas mulheres. Duca menospreza a esposa dizendo que ela quer ser uma "mulher liberada graças aos programas de TV que colocam ideias maldosas em sua cabeça", como se Clarice fosse um ser insignificante, incapaz de se posicionar como as "mulheres liberadas de hoje". Para ele, "liberada" é a mulher que quer ser independente e vai em busca de seus sonhos, mas continua sendo financeiramente dependente do marido, a quem ela deve respeito. $O$ agressor não se conforma com as aspirações de liberdade da esposa e por isso agride. Malu enfrenta o posicionamento reacionário de Duca, dizendo-Ihe sobre a hipocrisia e covardia de seu ato.

No dia seguinte, ela encontra com outra vizinha, interpretada por Dorinha Durval, também indignada com a violência doméstica e a mesma fala sobre os grupos de ajuda às mulheres vítimas de violência doméstica. Essa personagem aparece em uma cena crucial para elucidar algumas questões sobre violência doméstica. Seu tom de voz é alarmante referindo-se à condição da vida de Clarice. Segura algumas pastas e papéis com uma mão e, com a outra, a porta do elevador do prédio enquanto fala com Malu, caracterizando-a como uma mulher atarefada, mas engajada na causa por melhorias na vida das mulheres. É uma mulher ocupada com as atividades profissionais e alerta sobre a importância em convencer Clarice a frequentar os grupos de apoio. Aponta que os grupos também ajudam aos maridos agressores, para tentarem mudar seu comportamento. Finaliza comprovando que muitas mulheres não permanecem frequentado os grupos, por medo ou vergonha e a situação dentro de casa volta ao ciclo de violência.

Esse é um ponto interessante do capítulo pela divulgação das ações do movimento feminista em ajudar mulheres vítimas de violência, assim como a exposição de soluções legais sobre o assunto, na medida que as mulheres podem $\mathrm{e}$ devem denunciar judicialmente as agressões. Malu pondera que mesmo não havendo solução imediata com as denúncias em delegacias, que esta era uma ferramenta importante para mostrar as autoridades o grave problema que muitas mulheres vivem dentro da própria casa.

A reconciliação do casal no seriado acontece como previsto, ou seja, mesmo depois de inúmeras agressões a mulher retorna ao lar e, infelizmente, ao ciclo de 
agressões. Em geral elas voltam para o lar na tentativa de melhorar a relação ou em muitos casos por não terem para onde ir nem ter como se sustentar. Portanto, Clarice convida Malu e Elisa para um jantar em sua casa em comemoração ao retorno da harmonia de seu casamento. No final da noite, Duca, que já tinha bebido demais, se descontrola mais uma vez, agredindo a esposa na frente da Malu e da filha, que intercedem por Clarice e são ameaçadas por ele com uma faca. A cena trágica termina com a presença da polícia, Clarice decide não prestar queixa contra o marido e os policiais consentem dizendo "que se toda noite prendessem pessoas naquela situação a delegacia não teria espaço", confirmando assim a inadimplência dos órgãos oficiais.

No início dos anos 1980, O SOS Mulher foi criado em São Paulo, logo em seguida em Campinas e no Rio de Janeiro. Em Minas foi criado o Centro de Defesa da Mulher. Todas as entidades eram autônomas e tinham como objetivo atender a mulher vítima de violência, com um serviço de voluntárias que incluía psicólogas e advogadas. Em reação aos casos de homicídios ocorridos no ano de 1980, foi criado pelas feministas mineiras o slogan "Quem ama não mata". Além de atender a mulher, faziam grupos de reflexão sobre a violência e procuravam os meios de comunicação para promover o debate junto à opinião pública.

As feministas questionavam também a ideia de que a violência conjugal era um assunto das mulheres (ou homens) pobres, negras, ignorantes e de famílias desestruturadas. Outro questionamento importante à época foi o da absolvição dos assassinos de mulheres sob alegação de que teriam agido em legítima defesa da honra. Graças à pressão feminista e de alguns advogados esclarecidos, o poder judiciário passou a dar um novo tratamento à questão.

Podemos dizer que o movimento no Brasil elegeu duas estratégias: a ação direta no primeiro momento e a reivindicação de políticas públicas em seguida. $O$ movimento feminista brasileiro tem como uma marca própria a sua articulação com a reivindicação dos direitos sociais, mais do que com a noção de liberdade ou libertação das mulheres. (DINIZ, 2006).

Nas eleições de 1982, algumas feministas vinculadas ao PMDB, partido que ganhou as eleições estaduais aquele ano, reivindicaram a formação de um Conselho Estadual da Condição Feminina. Criado em 1983, apresenta quatro prioridades: 
creche, saúde, trabalho e violência. Foi criado o COJE (Centro de Orientação Jurídica e Encaminhamento Psicológico), em 1985, e foi criada a primeira Delegacia Policial de defesa da Mulher, em 1986. Essas iniciativas vão se estendendo por todo o país, como parte de uma agenda de reivindicações do movimento feminista, organizadas ou não em partidos, com ênfases e formatos diversos quanto aos serviços reivindicados.

Perante as conquistas que foram resultado das lutas dos movimentos feministas tanto nacionais quanto internacionais, que lutavam também pelo reconhecimento da mulher como um ser de direito, passou a ser questionado aos juízes, advogados, promotores, enfim, aos agentes jurídicos até quando a honra masculina valeria mais que a vida de uma mulher para o judiciário? Até quando a mulher seria a responsável direta em resguardar a honra de um homem? Através dessas reivindicações, da criação das primeiras delegacias de mulheres, a jurisprudência brasileira começou a ser menos tolerante com a alegação de legítima defesa da honra usada de forma arbitrária nos tribunais do júri.

Um dos casos mais importantes para o debate e a redefinição da jurisprudência brasileira em relação aos crimes contra a mulher foi o assassinato da socialite, mineira, Ângela Diniz pelo seu namorado Raul Doca Street, em 30 de dezembro de 1976, na casa de praia dela na cidade de Búzios, região dos lagos do Rio de Janeiro. O crime foi intensamente noticiado pelos veículos de comunicação gerando uma comoção nacional. As descrições do crime enalteciam as posturas pouco tradicionais de Ângela Diniz, como o hábito de consumir bebida alcóolica, fazer uso de drogas entorpecentes, ser uma mulher desquitada e que não possuía a guarda dos filhos, ou seja, a imagem construída pós assassinato foi baseada em valores morais na tentativa de desqualificar seu caráter. Enquanto o namorado, Doca, justificou a ação como um impulso de raiva causado por uma suposta traição de Ângela. Em entrevistas concedidas à TV Globo no início de 1977, ele assumiu o crime, afirmou que a amava muito e que sentia ciúmes por ela ser uma mulher muito bonita, independente, mas depois de uma briga em que Ângela queria terminar o relacionamento, inconformado, ele a assassinou com 3 tiros a queima roupa.

Doca Street foi julgado em 17 de outubro de 1979 pelo júri de Cabo Frio, cidade de que Búzios era distrito. A defesa foi feita pelo ex-ministro do Supremo 
Tribunal Federal, Evandro Lins e Silva, que conduziu a retórica em torno da legítima defesa da honra. Esse argumento foi aceito pelo júri popular que praticamente absolveu Doca do crime de assassinato, sendo condenado apenas a 2 anos e 2 meses de reclusão que nunca foram cumpridos por força de sursis. (SOIHET, 2006). Após a decisão do júri iniciou-se uma mobilização popular pedindo a anulação de tal julgamento. As lideranças feministas do Rio de Janeiro, São Paulo e Minas Gerais mobilizaram-se através do slogan "quem ama não mata", referindo-se ao crime passional que acarretou na morte de outras duas mulheres por seus maridos na cidade de Belo Horizonte. A economista e professora Hildete Pereira de Mello contou a época sobre a grande mobilização que se deflagrou depois do primeiro julgamento, em que foi pedido a revisão de pena, pela justificativa de que a impunidade seria uma grande ameaça para a sociedade brasileira. (SOIHET, 2006). Dessa forma, o julgamento de Doca demonstrava a maneira pela qual a sociedade brasileira resolvia as relações de poder entre os sexos, ou seja, o masculino poderia impunemente assassinar uma mulher que não correspondesse ao seu papel tradicional, transformando assim a vítima em culpada pelo crime.

No ano seguinte, a cobertura pelos jornais, em especial pelo Jornal do Brasil, sobre o caso Doca Street, foi intensificada, enquanto as reivindicações nas ruas por sua condenação continuavam. Em 17 de Junho de 1980 o jornal publicou uma reportagem sobre o lançamento do livro "A defesa tem palavra" de autoria do advogado de defesa Evandro Lins e Silva (JORNAL DO BRASIL, 1980a). O livro conta o duelo de oratória, acrescida de documentos, notas e comentários sobre a defesa de Evandro especificamente no caso Doca Street. Assim, é possível perceber a importância desse caso para a justiça brasileira à época, pois após a decisão do júri e as manifestações contrárias a ele, instaurou-se uma Comissão Parlamentar de Inquérito, ou seja, iniciou-se um debate institucional sobre a eficiência do júri popular no Brasil. A mobilização do movimento feminista foi fundamental para iniciar a discussão em torno do discurso da defesa da honra, e garantir a reflexão jurídica em torno dos casos de violência contra a mulher.

No final de julho de 1980 outros dois crimes estimularam as reivindicações das mulheres. Eloisa Ballasteros Stancioli e Maria Regina Santos de Souza Rocha foram assassinadas por seus respectivos maridos na capital mineira. Ambos, 
justificaram suas ações pela traição de suas mulheres. Em depoimento, Eduardo Rocha confessou o crime e explicou que "não permitia a mulher de fumar, vestir determinadas roupas, ou assistir programas de televisão como Malu Mulher" (JORNAL DO BRASIL, 1980b). As privações citadas pelo marido da vítima são exemplos de relações pautadas pela opressão. Assim, reforça que muitos casamentos aparentavam estabilidade por seguir normas e condutas aceitas por um padrão de sociedade, mas em seu interior, quando as relações de poder e dominação do marido eram subvertidas pela esposa, as consequências eram desastrosas para a mulher.

Por isso, é necessário lembrar que o medo da subversão é causado pelo temor da perda de privilégios. Quando o marido de Maria Regina Rocha a proíbe de assistir o seriado Malu Mulher ele reforça esse medo. A série apresentava temas cruciais para a pauta do movimento feminista dos anos 80 em especial o episódio "em legítima defesa da honra e outras loucuras" em que é representado o caso de violência doméstica. Antes, outros temas já haviam causado polêmica como "Ainda não é a hora" sobre o aborto e "A amiga" sobre homossexualidade. Dessa forma, impedir a esposa de assistir um programa de TV que fala sobre a mulher moderna e as possibilidades de sua emancipação, pode também ser entendido como o medo de perder seus privilégios garantidos pelo patriarcado. Nesse caso, o incômodo causado pela possibilidade de subversão da mulher a seu marido acabou tragicamente com a sua vida. Esses não foram os primeiros casos de esposas assassinadas por seus maridos, mas foram os de maior repercussão na imprensa, que levaram a pauta feminista sobre a violência adiante, possibilitando o desenvolvimento de políticas públicas em defesa da mulher ao longo da década de 80.

A mobilização de mulheres continuou intensa e em 19 de agosto foi realizado um ato no final da tarde na escadaria da Igreja São José, no centro de Belo Horizonte, para protestarem contra o machismo na sociedade e, em particular, contra os assassinos de Eloisa Stancioli e Maria Regina Rocha. A manifestação contou com a presença do movimento feminista do Rio de Janeiro e São Paulo. Foi lido pela jornalista Miriam Christus o manifesto da mulher mineira que condenava a prisão das mulheres casadas que ao almejarem a separação acabavam 
assassinadas. (JORNAL DO BRASIL, 1980c). Durante o ato público foi lançado oficialmente o Centro de Defesa da Mulher, uma entidade autônoma que tinha como objetivo atender a mulher vítima de violência, com um serviço voluntário de psicólogas e advogadas. Além de atender a mulher, faziam grupos de reflexão sobre a questão da violência e procuravam os meios de comunicação para promover o debate junto à opinião pública. (TELES, 1993).

\section{CONSIDERAÇÕES FINAIS}

A relação mídia e sociedade pode ser evidenciada depois das implicações do primeiro julgamento, com as reivindicações do movimento feminista e a produção do episódio do seriado Malu Mulher.

O programa de televisão que a época trazia à tona questões sobre a emancipação feminina e a vida da mulher moderna, também abordou a violência física que mulheres casadas sofriam por seus maridos. Ou seja, o programa Malu Mulher, nesse caso, aproveitou a discussão que ocorria sobre violência, em especial as notícias sobre mulheres assassinadas por seus companheiros, a repercussão do caso Doca Street e tantos outros que passaram a ser noticiados pelos veículos de comunicação de massa, para produzir um capítulo só sobre o tema, demonstrando assim uma dinâmica entre o que acontecia na sociedade e o que era reproduzido pela mídia. Não é à toa esta relação quando evidenciamos que o novo julgamento de Doca Street foi anunciado pela imprensa um dia depois da exibição do episódio em questão.

O próprio jornal comenta a similaridade da discussão que ocorria sobre o caso Doca Street e o episódio de Malu Mulher. Na coluna de Paulo Maia, publicada no Caderno B do JB em 30 de setembro, o colunista compara as situações da ficção com as da vida real "quando é agredida pela versão carioca dos mineiros machões, Duca, o "Doca” Street recriado por Gianfrancesco Guarnieri." (JORNAL DO BRASIL, 1980d). Maia faz menção aos casos de violência e homicídio contra mulheres em Minas Gerais que vinham sendo noticiados pelo próprio JB. O colunista comparou os protagonistas daqueles crimes, os "machões", ao personagem carioca, interpretado 
pelo ator Guarnieri, que não coincidentemente chamava-se "Duca", ou seja, um trocadilho com o nome Doca, assassino de Ângela Diniz.

No entrecruzar de fatos reais com a ficção, a coluna publicada no Jornal do Brasil colabora para sedimentar uma de nossas hipóteses sobre a relação dinâmica entre as produções dos veículos de comunicações de massa e as demandas sociais. Nesse caso, é possível notar que a agitação causada pelo movimento feminista no Brasil em torno da questão da violência contra a mulher ganhou uma maior repercussão midiática depois do caso Doca Street. Foi dedicado uma maior atenção para este problema que passou a ser mais divulgado, inclusive por outros casos parecidos, como os mineiros. E a repercussão na mídia não aconteceu apenas através de notícias, mas também com a produção de uma ficção para ilustrar a questão da violência contra a mulher.

É interessante notarmos que ao mesmo tempo que o crime ocorreu, o movimento feminista do Brasil mudou seu foco de reivindicação, passando então a lutar por questões referentes a vida da mulher como a sexualidade, os direitos reprodutivos e o combate à violência. Dessa forma, a repercussão nos veículos de comunicação de massa é diretamente proporcional às demandas sociais e se nesse caso estavam debatendo sobre a condição da mulher casada que sofria violência por seu companheiro, então esse era o tema que merecia ser midiatizado.

Portanto, entendo que o seriado Malu Mulher contribui para a divulgação das pautas de um movimento feminista brasileiro. Ele colabora ao trazer popularidade ao termo "feminismo", assim como trazer para a esfera pública questões como a interrupção voluntária da gravidez ainda discutidas no Brasil contemporâneo. Colabora com o debate referente a violência contra a mulher ao divulgar os grupos de apoio promovidos por feministas e com a questão da sexualidade feminina vistos com pudor à época. Mas ainda assim, dissemina e enfoca o feminismo liberal como a melhor opção de expressão do feminismo, uniformizando o movimento a uma única corrente, quando na verdade, sua heterogeneidade é a melhor forma para a nossa compreensão dele. 


\section{REFERÊNCIAS}

ALMEIDA, Heloisa Buarque de. Trocando em miúdos: Gênero e sexualidade na TV a partir de Malu Mulher. Revista Brasileira de Ciências Sociais, [S.I.], v. 27, n. 79, p. 125-137, jun. 2012. Disponível em:

http://www.scielo.br/pdf/rbcsoc/v27n79/a08.pdf. Acesso em: 29 jan. 2019.

CORDEIRO, Janaína. Do golpe de 1964 ao "milagre brasileiro": a campanha da mulher pela democracia (CAMDE). Ação política e imaginário coletivo. Iberoamérica Social: revista-red de estudios sociales. Sevilla, v. 1, p. 49-69, 2016. Disponível em https://iberoamericasocial.com/do-golpe-1964-ao-milagre-brasileiro-campanha-damulher-pela-democracia-camde-acao-politica-e-imaginario-coletivo/. Acesso em: 01 de fev. 2019.

DINIZ, Simone. Violência contra a mulher: estratégias e respostas do movimento feminista no Brasil. In: DINIZ, Simone; SILVEIRA, Lenira P.; MIRIM, Liz A. (org.). Vinte e cinco anos de respostas brasileiras em violência contra a mulher (19802005) alcances e limites. São Paulo: Coletivo Feminista Sexualidade e Saúde, 2006. p. 7-15.

JORNAL DO BRASIL. Como é chatinha essa Malu. Caderno B, Rio de Janeiro, 30 set. 1980d.

JORNAL DO BRASIL. Delegado se irrita com a versão do paisagista. 1. Caderno, Rio de Janeiro, 20 ago. 1980b.

JORNAL DO BRASIL. Mulheres protestam contra violência do homem mineiro. 1. Caderno, Rio de Janeiro, 19 ago. 1980c.

JORNAL DO BRASIL. Televisão: A juíza Joan Klein diz que ninguém está acima da lei nos Estados Unidos. Caderno B, Rio de Janeiro, 17 jun. 1980a.

REIS, Daniel Aarão. Ditadura e democracia no Brasil: do golpe de 1964 à Constituição de 1988. Rio de Janeiro: Zahar, 2014.

SOIHET, Rachel. Feminismo ou Feminismos? Uma questão no Rio de Janeiro nos anos 1970/1980. In: SEMINÁRIO INTERNACIONAL FAZENDO GÊNERO, Florianópolis, 2006. Anais eletrônicos [...]. Florianópolis: UFSC, 2006. Disponível em: http://www.fazendogenero.ufsc.br/7/artigos/R/Rachel_Soihet_40.pdf. Acesso em: 10 mar. 2019.

TELES, Amelinha. Breve História do Feminismo no Brasil. São Paulo: Brasiliense, 1993.

Recebido em 24/04/2019.

Aceito em 16/12/2019. 